\title{
College Management System Exploration Under the Internationalization of Higher Education
}

\author{
Wang Ke \\ School of Economy and Management \\ Shenyang Aerospace University \\ Shenyang City, China
}

\begin{abstract}
With the constant progress of economic globalization, the internationalization of education has become a trend. In such context, the colleges shall first understand the essence of the higher education internalization and the current status of the advanced education in our country before they make correct response. This is also the precondition for the research on how the colleges shall improve the management system. The thesis aims to research the education status in our country, under the condition of higher education internalization, analyze college management system to promote the integration with international education system. In today's trend of economic globalization, any country cannot stand alone away from the international background. We shall more frequently take part in international competition and constantly improve our international influence and position. As far as the current educational condition concerned, the shortage of international talents has begun to loom up in our country. Therefore, we still face some deficiencies in our current education internationalization measures. In recent years, our country has been paying more and more emphasis on the trend and constantly improving higher education reform. The colleges shall identify the inevitable trend of higher education internationalization and realize that educational globalization requires joint efforts of the government, society, school and individuals. It is utterly important for any college to find the management system suitable for its own development characteristics.
\end{abstract}

Keywords-Education; Internationalization; College

\section{THE ESSENCE OF HIGHER EDUCATION}

\section{INTERNATIONALIZATION}

The internationalization of the higher education can be construed as integrating the education in all countries together and absorbing the essence. For our country, it refers to the education mode combining overseas advanced education experience with the education work in our country. Since different experts hold different views on higher education internationalization, we will mainly focus on the following two modes: the mode with focus on concept internationalization, and the mutual exchange and communication between domestic and overseas education to realize the sharing of the international education resource and results; and the mode with focus on teaching content dividing teaching content internationalization into three aspects: I. educational result sharing and thee mutual development in educational content to realize education internationalization; II. talent cultivation which requires the modern college students to improve themselves and meet challenges in the wave of higher education internationalization; III. economic globalization based on educational globalization---education and economy cannot go without each other, and the intermingling of each country's culture can constantly push global education reform.

\section{THE REQUIREMENT OF HIGHER EDUCATION}

INTERNATIONALIZATION BACKGROUND ON COLLEGE MANAGEMENT

In the internationalization environment, there has been new requirement on college management which can be reflected from three aspects: cultivating new internationalized talents, the internationalization of academic research and the internationalized human resource management mode. The three aspects will be analyzed one by one in the following part.

\section{A. Cultivate new internationalized talents}

Currently, higher education internalization is mainly reflected in college students exchange program and overseas education. In recent years, the number of Chinese students seeking overseas education is increasing year by year. The "going-abroad" mode is right the development characteristics of our education; meanwhile, we are also paying attention to talent absorption and have made some positive adjustment in the policy of accepting international students, dedicating to build the biggest overseas student destination in Asia to realize the internationalization of education. That is also a way to demonstrate our education achievements and excellent national culture to all the other countries. In this way, we have raised some new requirements in college education, asked for reforms on the setting of teaching structure, curriculum and management system to suit the new mode of internationalized education, strengthened the exchange between the colleges in different countries, and emphasized the comprehensive quality of the students in evaluation system; meanwhile, while accepting overseas students and the students for overseas exchange program from different countries, we shall work out special management system based on the characters of these countries to get the students adapted to campus life as 
quick as possible and promote cultural communication and development.

\section{B. The internationalization of academic research}

Education internationalization can be academically reflected as academic internationalization which is also a concern of the academic world in recent years. The high-level college academic research in our country has successfully integrated into intentional academic competition, and in almost all the colleges, advanced international academic evaluation system has been introduced into academic research management to make it more standard in our country and better recognized by the international academic circle. Academic research is a large part of college teaching activity, and the research result can impact the academic position of a college. Under the background of internationalization, the management system for college academic research is under constant reform and going towards international standard either in policy or in mode; simultaneously, the requirement for the researchers are also going high, asking for not only the corresponding academic level and also the international vision and foreign language level, so that they can better display their academic achievement.

\section{The internationalized human resource management mode}

A high-level faculty is the key to the international education competition. As the education internationalization trend is going deep, more and more teacher experts are flowing in the international market, making human resource management quite important to attract and maintain the excellent education workers. As we are getting more and more aware of the importance of talents, we can see all the colleges are constantly enlarging the efforts in human resource management. The traditional concept on human cost is changing and the new one is being deep-rooted in our heart. In terms of management mode, we shall change the traditional concept, turn management into service and make more education workers feel the cherishment of the college for them to stimulate them to make more contribution. Around the important topic of human management, we can take reference from the equivalent or higher level of management mode, and build a strong talent team with an international vision to attract more talents for internationalized education.

\section{THE PROBLEMS IN CURRENT COLLEGE MANAGEMENT}

\section{A. The teaching management system to be reformed}

Teaching management is an important part of college management system, mainly responsible for the normal operation of teaching activities and teaching order maintenance. The major problems in our college teaching management are the large amount of tasks and the lack of rationality in duty arrangement. Teaching management is covering all the teaching activities in a wide and complicated range from curriculum to exam arrangement.

With some college management mode as the analysis case, it can be seen a common second-level management mode in colleges. The educational administration department has to take a host of tasks, too complicated to make sure normal management on the teaching activities once in face of a large quantity of programs and students. The disadvantages of this mode can mainly be seen from the following three aspects: power distribution---the secondary management mode largely centralize the power to the educational administration department, making the students and teaching and research office hard to participate in school management; the imperfect regulations and rules---in the secondary management mode, there is not a rational system to restrict the management and arrangement of school work, leaving to a strong randomness and low efficiency and badly affecting the normal going of school management; lack of innovation----under the background of education internationalization, all the colleges shall be ready to meet challenges, adapt to the international stage an make constant innovation in management mode. Purely following the old management mode may get the school to lose its competitiveness.

\section{B. The old concepts and views of the managers}

The traditional concept has no longer been applicable in the new context, but the managers in some colleges still have not accepted the open concept. The old concept has blinded their eyes, making them difficult to keep up with the international step and get aware of the current international environment. As a result, they lack intellectuality in question analysis and ignore the development of the knowledge talents' potential and the cultivation of the internationalized talent while focusing only on knowledge communication.

\section{The reverse of faculty power and talent cultivation}

First, analyze the faculty construction. The incomplete faculty allocation may lead to fewer chances for international academic communication, which will ultimately affect our participation into international education. In the process of faculty building, purely imposing various requirements on teachers without providing international learning chances and environment has seriously hindered the faculty construction. While analyzing talent cultivation, the most critical point lies in the improper curriculum. Currently, the curriculum is arranged not in combination with the actual conditions of the students and national demands for talents, and ignores cultivating the practice ability of the students. Innovative ability is always one of the important parts of talent cultivation and the necessary quality of the internationalized talents.

\section{THE OPTIMIZATION OF COLLEGE MANAGEMENT} SYSTEM TO CONFORM TO EDUCATIONAL

\section{INTERNATIONALIZATION}

\section{A. Constantly pushing management system reform}

For the colleges, the authority shall identify the international environment at current stage, and at the same time take reference from the advanced management experience for innovation in combination with the actual conditions of the colleges. This constitutes the basis for the international competition. Meanwhile, it is required to 
understand the changing rule of the education internalization, change the traditional concept on the administrative management and gradually shift it to developmental management. Make management system reform by law and bring the initiative of each department into full play to get the managers fully aware of their own responsibility, and improve their participation degree and management efficiency. While setting the management institutes, make full use of the existing resources of the colleges to gradually form a set of rational management system and emphasize the internationalized management concept to keep up with the times.

\section{B. Faculty construction by department coordinative management}

The teachers can be cultivated by selecting some of their best for overseas communication, allowing them to get integrated into the overseas customs and bring back the advanced international experience and the latest teaching mode. This mode can strengthen their international concept and ability, and overcome their deficiencies. Therefore, we are required to constantly enhance the international level of the college management, provide favorable guarantee for the teachers, regularly organize international communication for teachers to get them exposed to international cultivation any time, and at the same time, learn the advanced management experience of the advanced colleges to upgrade the management mode.

\section{Information management department conforming to the international trend}

College information network management department is utterly important for college international management system; because it is related to various advanced teaching achievements or the absorption and introduction of the teaching system. Now that educational internationalization has been inevitable trend, the college shall keep track of the latest international dynamic status, gradually adapt to it and make corresponding reforms. It is required to strengthen propaganda efforts, create international education atmosphere at school, and combine together the informatization mode with internal management mechanism to constantly improve management efficiency. Meanwhile, establish an international information communication platform and publish on the platform the information about international education, so that the students can grasp the latest information and better improve themselves. Information management department is the important department receiving the external information, and its efficiency in adapting to the international trend is related to the internalization goal of the whole school.

\section{CONCLUSION}

College students are the successors of the future of the nation, and colleges are the sites where the college students are trained and cultivated; therefore, it is quite important of the colleges can conform to the internationalization background and realize innovation in management system under such background. Colleges shall have enough courage to face the problems in the current management mode, change management concept, absorb the advanced management experience from abroad, but without blindly copying their experience which may get our education the dependent of the foreign country instead of promoting the internationalization trend. What matters in the practice is innovation, since the constant reform on management system can get the colleges well integrated into the international environment and cultivate more compound talents to improve our education position in the world.

\section{REFERENCES}

[1] Huang Ying, Fu Changluan, Gou Jianhua. College Management System Exploration under the internationalization Background of Higher Education [J] Education Science \& Culture Magazine (the middle-term issue), 2013,05:5-6+10

[2] Li Zongyu, Analysis on College Education Cost Calculation based on Activity-based Costing [J] Adult Education, 2013,09:93-95

[3] Wei Wenqi. College Management System Exploration under the Internationalization Background of Higher Education [J], Brand (the second half of the year), 2015,01:113

[4] Li Jingrong, College Management Construction under the Internationalization Background of Higher Education [J], Human Resource Management, 2012,01:116-117

[5] Feng Yun, Wangqi, Higher Education Performance Management System Exploration [J], China's Higher education [J] Chinese higher education, 2012,07:18-21

[6] Wang Yazhuo, $\mathrm{Xu}$ Tongwen, American Higher Education Internationalization and Applied Talents Cultivation [J], 2012,06:54-57.

[7] Teng Yuqing, The prominent Problems and Strategies in College Foreign Affair Management Work under the Internationalization Background of Higher Education [J], Chinese Market, 2012,52:113-115

[8] Fang Xi, Research on Building College Bilingual teaching Quality Guarantee System---based on Higher Education Internationalization [J] Huzhou Normal University Journal, 2014,01:107-111.

[9] Deng Rui, Tibet College Foreign Affair Management Research under the Internationalization Background of Higher Education [J], Changchun Education College Journal, 2014,01:122-123.

[10] Yang Lin, College Talent Cultivation Path Exploration under the Internationalized Vision of Higher Education [J] Jiangsu Higher Education, 2014,04:112-113.

[11] Su Bo, Bilingual Work---Building College Service Platform in the Context of Internationalized Development of Higher Education $[\mathrm{J}]$ Modern Marketing (the last ten-day period issue of month), 2014,06:140-141.

[12]Yu Shi, Wei Xiaoyan, Problem and the Analysis on the Optimization Path to the Solution in College Teaching Management under the Internationalization Background of Higher Education [J]. Academic Forum, 2014,08:171-174.

[13] Zhao Zhibo. College Quality Management System Building at the Stage of Higher Education Popularization [J]. Anshan Science and Technology Journal, 2006,01:106-108+112.

[14] Cui Li, Zhangsen, Chinese College Response Strategy under the Internationalization Background of Higher Education [J], Hebei Journal, ,2013,06:179-182. 